\title{
Browsing to Breathe: Social Media for Stress Reduction
}

\author{
Rebecca Coates \\ Loughborough University \\ R.C.Coates@lboro.ac.uk
}

\author{
Martin Sykora \\ Loughborough University \\ M.D.Sykora@lboro.ac.uk
}

\author{
Tom Jackson \\ Loughborough University \\ T.W.Jackson@lboro.ac.uk
}

\begin{abstract}
In a pressurized world, it is important that research continually works towards discovering new ways to improve the mental and physical wellness of society. Traditional approaches for measuring stress have been vastly explored, however rising concerns for chronic stress calls for new methodologies to sense stress on Social Media, which, as a tool, could provide valuable insight into wellness.

Over a period of two-weeks, a rigorous mixed methods approach (daily surveys, Social Media data collection and post-study interviews) aided the discovery that Social Media, particularly browsing, can improve the wellness of placement students, as it helped them to cope with stress. The adoption of an established coping survey for stress helped in the identification of behavioral differences between participants. This paper explores the positive impact that Social Media can have on stress and highlights the potential of digital coping mechanisms.
\end{abstract}

\section{Introduction}

Research in the field of mental health and wellness largely criticizes Social Media (SM) as dangerous, with platforms such as 'Instagram' being held accountable for creating 'perfect' images which can lead people to rate themselves against impossible standards [33]. Indeed, it is right to be cautious regarding the impact of these SM platforms. However, our paper demonstrates that digital technology, and specifically research in the field of SM, should be skeptical of this stance so as not to disqualify the benefits SM can have.

More specifically, according to research [42], there are several indications that the Internet is of rising importance when it comes to dealing with stressful situations and it is fairly common for individuals to mobilize at least some type of online resource after experiencing a negative life event [38]. It is vital to reveal patterns of behavior that exist in stress reduction, so society can be empowered and adopt self-management techniques [25,28].

Fundamentally, chronic stress has resulted in a wide range of negative societal impacts, such as mental health conditions, with $4.4 \%$ (332m) of the global population suffering from depression [41], and even premature death ( $60 \%$ of all deaths are a result of chronic diseases with chronic stress linked to the six leading causes of death) [8]. Personal circumstances (genetic, mental and financial, for example) can make some populations more vulnerable to the negative effects of stress. Lederbogen et al. [22], amongst others [20], have explored the effects of city living, discovering that this is linked to social stress. Other controls such as personality, social norms, relationships and situational factors, as demonstrated in research by Beaton [4], can also encourage someone's coping strategies, as these tend to dictate acceptable ways to deal with a problem [1]. In light of this, it can make stress difficult to identify, predict, and measure [22].

Despite these difficulties, the growth of people interacting online on a regular and frequent basis has prompted a new area of research which offers the potential to determine the role SM plays in coping with stress, and possibly provide early intervention. There is evidence of SM as a cause of stress, which has been accounted for throughout this paper [15]. As this continues to grow in popularity, SM has a greater responsibility and role for the monitoring of early stress detection and stress reduction, acting as a coping resource. Through the monitoring of SM, live data collection provides researchers with real-time information which gives an indication of the feelings, thoughts, emotions, social lives and everyday activities of users [29]. Using this data, researchers [37] have demonstrated that data from Twitter can provide accurate offline results.

This research paper expands upon this motivation and explores the benefits of additional channels (Facebook, Instagram and Snapchat) using a mixedmethod design of surveys, SM data collection and post-study interviews. The aim of the study is two-fold 1) To discover if and how SM is used to reduce stress 
and 2) To discover patterns of SM use, adopting The Ways of Coping Survey (WAYS). We discovered the benefits of SM browsing for stress reduction amongst placement students in London, England.

This paper is structured as follows. Firstly, a theoretical evaluation of the empirical context of 'Stress', 'SM' and 'Coping' is offered. Next, a longitudinal (2-week) mixed-methods study is presented, adopting Skinners coping framework [36] (adapted by Gaspar, [13]), followed by preliminary qualitative and quantitative results with focused discussion about the role of SM and user behavior on 'high stress' (HS) days compared with days when 'stress is lower' (LS). Finally, we conclude the contribution of this paper in relation to selfmanagement for wellness and avenues for follow-up in a health context.

\section{Theoretical Background}

\subsection{Stress in the Digital Age}

For this paper two definitions are provided, both of which are taken from the field of Psychology. Stress is a term that professionals have trouble defining and no single agreed definition exists [17], however, for the purpose of this research, it is defined simply as 'The result of an imbalance between demands and available resources' [21], and 'Stress Response' as 'the organisms adaptive behavioral, cognitive and physiological responses to challenging, harmful conditions' [34]. According to Monroe [27], a stress response involves various processes from gene expression to different social interactions. Traditionally, stress was primarily measured through personal contact with a healthcare professional (i.e. measuring heart rate and pulse) [7] or via perception surveys (The Perceived Stress Scale) [6,39].

WAYS is the most widely used tool for measuring coping style and identifies eight strategies that people adopt as follows: Confrontive Coping, Distancing, Self-Controlling, Seeking Social Support, Accepting Responsibility, Escape-Avoidant, Planful Problem Solving and Positive Reappraisal. Stress manifests itself differently, and within this, people take different approaches dependent on the stressor [11].

Society is increasingly observing the incorporation of technology using mobile applications and other self-management techniques, although research is relatively limited [25]. The literature notes that technology has its place in helping society and disapproves of those who say that technology and science cannot be combined 'The way a person copes with stress is an important mediator of the stress response and outcome' [18,23]. There are several ways in which technology may be a way that people are dealing with stress, thus it is important to explore these indicators in light of the dangers of chronic stress.

\subsection{Online Coping Behaviors}

Online coping can be defined as 'The thoughts and behaviors facilitated by the Internet that help to manage stressful situations' [12]. The literature suggests that the utilization of SM can be a form of affirmation for people of all generations as it provides users with the opportunity to feel heard in their social community. It can help reduce loneliness by allowing people to virtually connect with members of their geographically based communities (online communities), to exchange information, and provide access to medical information for self-empowerment as 'e-consumers' [2,30,35,42].

Van Ingen and Wright [38] study the mobilization of online and offline coping resources. They discovered that $61 \%$ of people have used the Internet for some form of coping and found support for social compensation (low self-esteem and isolated individuals add more online resources to their mix of preferred coping strategies than their counterparts). They however acknowledge that their data is based upon retrospective questions collected in a 3-year old survey and recognize the limitations of the human memory [38]. This is particularly important for city dwellers. Lederbogen et al. [22] asked participants confusing mathematical problems in a pressured situation and observed the activity of the amygdala and the perigenual anterior cingulate cortex. They discovered that city dwellers' brains looked more active compared to those not living in cities. Further to this, a high prevalence of anxiety (dopamine) was found in city dwellers $[19,20]$.

\subsection{Social Media as a Measurement Tool}

SM is providing new research opportunities for the collection of data relating to both measurements of stress and coping [6]. No studies to date have looked specifically at collecting both online and offline data relating to measurements of stress, although research that explores the simultaneous appraisal of both online and offline mobilization of coping resources does exist [38]. This enables the analysis of the relative importance of online (versus offline) coping, however provides no insight as to their real-time usage. Offline data provides the researcher with detailed insight into the demographics/background of each participant, 
which allows for clarity in relation to individual differences in analysis and discussion. Moreover, direct contact with participants builds a relationship of trust, which encourages participants to proceed with the study and ensures that their wellness is nurtured. This was particularly important in this study where students may have felt vulnerable. In comparison, studies that only collect large SM datasets, such as [14], often miss out on the detail of each person, which is arguably needed in the understanding of human behavior and for interventions that are tailored to individual needs.

Studies have been carried out that provide evidence for the measurement of a range of aspects relating to the individual psyche using SM. With regards to mental health, De Choudhury et al. [9] demonstrate the potential of Twitter as a tool for measuring and predicting major depression in individuals. They found that individuals with depression demonstrate lowered social activity, high self-attentional focus, greater negative emotion, increased relational and medicinal concerns, and heightened expression of religious thoughts. Moreover, there was an apparent closeness in their networks. Similarly, academics have developed tools for the prediction of election results based upon Tweets (EMOTIVE) [37], and coping style [14]. Recent research [24] concludes that emotions and sentiment expressed in Tweets have the potential to provide real-time monitoring of stress level and emotional wellness in college students.

\subsection{Summary}

'Stress' and 'Coping' have evolved throughout the years and there is a need to understand the influence of SM for wellness and stress reduction, balancing the research that establishes a negative stance towards SM. Further, research $[12,18,23]$ suggests that technology and the Internet play an important role in coping, and thus should be explored extensively. The literature discussed $[2,23]$ demonstrates that the digital era has created challenges and opportunities, i.e. increased availability to hi-speed $\mathrm{Wi}-\mathrm{Fi}$ and data connections, which provide ease of communication and SM usage.

The research gap that this paper aims to address is to establish how SM methods can assist in understanding stress reduction via SM and theoretically, the influence SM has in the field of coping for wellness. As discussed previously, few studies have addressed the use of SM interaction as a measure of stress. In light of this, it is becoming increasingly important to understand how SM shapes one's experience of stressors and influences how individuals perceive SM as a channel for coping. This is something that others [38] have begun to investigate, demonstrating $\mathrm{SM}$ as a way of social compensation. Their study, however, relies solely on the use of surveys. In this paper we recognize the importance of this research, however suggest that live SM data collection, followed by immediate qualitative interviews, prevents the limitations of the human memory having an impact on the result.

This research aims to eventually design a framework that assists the population (both medical and lay SM users) with an understanding as to how best to manage their SM use, through knowledge of the impact of channels for varying coping styles. The WAYS was selected as the most appropriate tool for determining coping style, despite considering other surveys that have been used such as that used by [38]. It was decided that this offered validity having been previously utilized extensively.

\section{Research Method}

This section describes the mixed-methods approach used for this research. McKim [26], amongst others, suggest that methods of this type add value to the research, although they require additional time due to the need to collect and analyze two different types of data [26,31].

\subsection{Research Aims and Study Population}

As introduced previously, the aim of the study is two-fold 1) To discover if and how SM is used to reduce stress and 2) To discover patterns of SM use, adopting WAYS. We anticipate that meeting these aims will contribute knowledge of SM in relation to wellness and develop a grounding for academics for continual investigation.

The study consisted of 38 participants who were completing their industrial placement in London, England (19 participants finishing in sample 1 (S1), and 19 starting in sample 2 (S2). It was decided that this is a sufficient number of participants in light of the nature of the study: a mixed methods longitudinal approach collecting data for each participant over a 2week period. Furthermore, it is not anticipated that the results be generalized.

Although not as stressful as events such as the death of a loved one or marital separation, it is likely that the combination of starting a new job and moving to new accommodation at the beginning of their placement was more likely to increase the levels of stress when compared to those completing their placements [28,31]. All participants moved over 150 
miles from their place of study to their place of work. To identify participants, a placement office within a University School was contacted requesting the details of Undergraduate students who were currently undertaking their placement within London-based businesses - this consisted of over 460 students. After the study gained clearance through the institutional ethics approval process, students were each contacted via email requesting their participation in the study. Participants were told that the study was concerning their SM activity and how this relates to their wellness. A total of 38 (8.3\%) returned the request (19 towards the end and 19 the beginning of their placement). When entry surveys were complete, the researcher screened the SM accounts to confirm there is sufficient social media activity, i.e., data.

Table 1. Participant Demographics

\begin{tabular}{|c|c|c|c|c|c|c|c|}
\hline \multicolumn{3}{|c|}{$\begin{array}{c}\text { Finishing Placement } \\
\text { (S1) }\end{array}$} & \multicolumn{3}{c|}{$\begin{array}{c}\text { Starting Placement } \\
\text { (S2) }\end{array}$} \\
\hline \multicolumn{2}{|c|}{$18-21$} & \multicolumn{2}{|c|}{$22-25$} & \multicolumn{2}{c|}{$18-21$} & \multicolumn{2}{c|}{$22-25$} \\
\hline $\mathrm{M}$ & $\mathrm{F}$ & $\mathrm{M}$ & $\mathrm{F}$ & $\mathrm{M}$ & $\mathrm{F}$ & $\mathrm{M}$ & $\mathrm{F}$ \\
\hline 4 & 12 & 1 & 2 & 8 & 11 & 0 & 0 \\
\hline
\end{tabular}

\subsection{Data Collection}

Participant identification was rolling from May until September 2016 (split between Semester 1 (completing placement) and Semester 2 (commencing placement)). Following contact via email, entry surveys with consent were distributed. The goal was to gain demographic information/availability and details regarding SM usernames for enrolment in the study.

SM data was then collected by the primary researcher (this took place in 2016), and was multimedia, i.e. textual, image and video, from all SM channels identified in the entry survey - most frequently Facebook, Instagram, Twitter and Snapchat. This allowed for an entire picture of their SM usage to be considered in analysis. This was coded according to prior coping models by Skinner et al. [36] and Gaspar et al. [13]. Data were collected from each participant for 2-weeks during this time-frame. Participant demographics are shown in Table 1. It can be noted that there is quite a large gender divide with a higher female response rate for $\mathrm{S} 1$, which is a limitation of the study.

During the 2-week period, subjects were daily sent an electronic survey (Table 2) via their preferred choice of contact. This was used to collect Likert scores regarding their stress, stress reduction and use of SM. Likert scales have been used frequently in
Table 2. Daily Survey

\begin{tabular}{|c|c|}
\hline Question & Scale \\
\hline 1. How stressful was your day? & $\begin{array}{l}1=\text { Not at all } \\
7=\text { Extremely }\end{array}$ \\
\hline $\begin{array}{l}\text { 2. If you've been active on SM today, } \\
\text { did this relate to how you felt at the } \\
\text { time? }\end{array}$ & $\begin{array}{l}1=\text { Not at all } \\
7=\text { Entirely }\end{array}$ \\
\hline $\begin{array}{l}\text { 3. To what extent did your use of SM } \\
\text { help to reduce your overall stress } \\
\text { levels? }\end{array}$ & $\begin{array}{l}1 \text { = Not very helpful } \\
7 \text { = Very Helpful }\end{array}$ \\
\hline $\begin{array}{l}\text { 4. If Social Media did help to reduce } \\
\text { your stress today, to what extent did } \\
\text { active engagement (likes, posts, } \\
\text { comments etc.) help? }\end{array}$ & $\begin{array}{l}1 \text { = Not very helpful } \\
7 \text { = Very helpful } \\
\text { N/A = Not applicable }\end{array}$ \\
\hline $\begin{array}{l}\text { 5. If SM did help to reduce your } \\
\text { stress today, to what extent did } \\
\text { browsing help? }\end{array}$ & $\begin{array}{l}1 \text { = Not very helpful } \\
7 \text { = Very helpful } \\
\text { N/A = Not applicable }\end{array}$ \\
\hline $\begin{array}{l}\text { 6. Was SM the cause of your stress at } \\
\text { all today? }\end{array}$ & $\begin{array}{l}1=\text { Not at all } \\
7=\text { Entirely }\end{array}$ \\
\hline $\begin{array}{l}\text { 7. Please provide a comment to } \\
\text { describe your usage today. }\end{array}$ & Textual \\
\hline
\end{tabular}

medical research and upon screening measurement surveys, i.e. The Post Traumatic Stress Survey [32], this was evaluated to be a suitable approach for the nature of the research (self-reported scoring). Debates exist as to whether a Likert scale of 1-5 or 1-7 be used for data collection and which is the most suitable measurement scale. There is a mid-point on both scales which allows for neutrality in both cases. Considering the study aims, it was decided that a larger range would provide more detail in analysis.

The questions for the daily survey were created based upon a review of the literature, in particular that surrounding stress measurement scales and tested using a rigorous pilot study which involved follow-up evaluative questions (adjusted accordingly) [5,7,32]. In total 532 surveys were collected (evenly split S1 and S2).

SM activity was collected for the two-week period from the following platforms (Facebook, Twitter, Instagram and Snapchat) with data collected from additional channels (i.e. Tumblr) where indicated by participants on the entry survey that was distributed prior to commencing the study.

The method of SM data collection evolved as the research progressed, beginning by capturing screenshots from platforms, progressing to the capture of SM content via mobile phone with a connection to 
QuickTime player for video (this allowed for additional audio and visuals to be collected).

Following the two-week period, participants were sent an exit survey and WAYS Questionnaire [10] (Table 6 displays the breakdown for each participant).

The exit survey gathered details regarding stressors experienced during the data collection period (to measure their stress baseline) and requested information regarding their experiences throughout the study (e.g. whether their activity on SM related in any way to experiences in their immediate surroundings).

Finally, consent was given by 20 participants who were contacted for an interview on their preferred channel (i.e. Skype, Facetime or mobile) for a followup discussion to gain further insight into their SM activity and aid context. This was a semi-structured interview, using responses as prompts for follow-up questions. This approach was chosen as the most suitable considering the nature of the interview (follow-up based upon the unique experience of each participant). This approach allows for participants to provide the most detail through exploration of their own journey and dataset, which was drawn upon by the interviewer [40].

\section{Analysis}

\subsection{Quantitative Analysis}

This section describes the approach of quantitative analysis utilized for this research.

Preliminary statistical averages were calculated to answer the first aim: to find out whether SM is used to reduce stress. These were determined for each of the Likert questions. Each of the quantitative averages (except self-reported stress score) were correlated against LS and HS scores as shown in Table 3. This helped to determine the first aim of whether there are different SM positives/negatives. Further to this, these statistics were used to discover whether stress was higher for those beginning placement (S2).

To address the second aim, analysis was undertaken to identify WAYS strategies that can be identified for those in the study that may provide insights into an individual's use of SM for coping. This approach provided an insight into stress, enabling initial profiling to be built for individuals. Raw scores describe the coping effort for each of the eight types of coping. High raw scores indicate that the participant often used the behaviors described by that scale in coping with the stressful event. For scoring, the score for each item on the scale was added together to provide a total. There are four possible responses that users can select $(0,1,2$, and 3$)$, which are also the weights that are used for determining the results [10]. The output of these calculations can be found in Table 6 , which displays the frequency of each Way of Coping strategy within the dataset. Note that multiple participants adopt several coping mechanisms.

Finally, statistical tests were carried out for validity confirmation. Despite the small sample of participants (38), we believe that the number of responses from the daily surveys (a total of 532 as each participant is tracked for 14 days), is an adequate sample size for statistical tests to hold some value. We do however acknowledge that a larger sample would increase this worth and would be useful in future studies.

\subsection{Qualitative Analysis}

This section describes the approach of qualitative methods of analysis utilized in this research. The videos were split into a series of images that were imported into software for coding according to a twostep coding strategy. 1) Adobe Lightroom was used to tag/code the images for ease of retrieval and pattern identification and 2) NVIVO was used to code the data according to the framework proposed by Skinner/Gaspar $[13,36]$. Textual survey and interview data was coded thematically.

Textual qualitative analysis is complete (from surveys and interviews), however more time is needed to fully understand the complex nature of the SM data - a full-break down of this is not yet provided. We aim to provide these results in a future paper. This analysis adopts the framework provided by Skinner et al. [36], adapted by Gaspar et al. [13]. This framework was chosen as the most suitable for assessment in a SM context in light of the breadth of coping approaches it analyzes.

Content was firstly coded by quantitative data, i.e. LS and HS days - to find patterns. Subsequently this was coded according to Skinners families of coping, adopting a validation approach (both by the researcher and externals). To provide an example, snapchats that included other people show that the participant was not alone at the time, possibly indicating social support. We then analyzed the quantitative data to divulge detail in regard to whether their stress was reduced/increased following this occasion.

Based on this coding, we were able to identify the similarities and differences in SM behavior on days which were highly stressful for placement participants (where participants selected either number 6 or 7 on the Likert Scale) versus those days when stress was lower (where participants selected either number 1 or 2 on the Likert Scale). 


\section{Findings}

\subsection{Social Media for Stress Reduction}

In the first part of this section we analyze the data to determine the impact SM can have on reducing stress and the impact on gender differences in behavior. Firstly, the average stress for S1 (finishing placement) was 2.74 compared to 2.79 for S2 (commencing placement). This is arguably only a slight increase, however, this does not discount the findings that can be drawn, although we may have expected this difference to be larger. Interview data shows that at the start of placement work was relatively straight-forward with little demand on participants.

Table 3 shows that on days when stress is high (indicated by a participant selecting either number 6 or 7 on the Likert scale on the daily survey), participants also indicated an average stress reduction score (as a result of SM) of 2.81, compared to a lower score of 1.92 when a lower stress score was indicated (shown by a participant selecting either number 1 or 2 on the Likert scale on the daily survey). This suggests that participants acknowledge SM as a tool for reducing their stress which is supported by an average score of 2.74 for relationship to feelings at the time.

\subsection{Browsing for Stress Reduction}

The rich qualitative results (from daily surveys and follow-up interviews) suggest that SM is more likely to be used for coping when there is the opportunity to access a mobile phone. SM browsing is often reported to be used during or after work as a distraction from a stressful day (i.e. when a stressor arises or for relaxation on a commute). Participants would also browse SM due to boredom. SM is less likely to be used as a coping mechanism when work is busy due to a lack of time, as demonstrated in Table 5: extracts (a) and (b). Interestingly it was males that were more likely to make this comment. This can be supported by the quantitative results shown in Table 3 which display an average stress reduction (SM browsing score) of 3.21 when a highly stressful day has been indicated by a participant selecting either number 6/7 on the Likert scale.

Furthermore, participants felt more in control of this platform as they can manage their audience, in contrast to Facebook where 'unfriending' someone can cause stress. Evidence for this can be seen in Table 5: extract (e) which is an example of a consistent finding within the study, particularly when interviewing females. The extent to which SM causes stress depends on the current emotional state of a participant. For example, in the case of extract (e), participant 19 was feeling emotionally sad, and to combat this she unfollowed those who increased her stress (on Instagram), and redirected her attention, 'followings', towards posts that would reduce her stress instead. In addition to this, females were more likely to comment that SM had caused their stress when stress levels were high and SM stress reduction was low, see Table 5: extracts (c), (d) and (e). These findings suggest personality and gender differences in the use of SM for both stress reduction (and increase), providing support for studies conducted by Pew $[15,16]$ who found that females were more likely to be stressed by SM, as well as find SM to be a good resource for coping with stress.

Table 3. Daily Likert Scale Results

\begin{tabular}{|c|c|c|c|c|}
\hline & \multicolumn{2}{|c|}{$\begin{array}{l}\text { Stress Score } \\
\text { (indicated on } \\
\text { the Likert } \\
\text { scale) }\end{array}$} & \\
\hline & & $1 / 2$ & $6 / 7$ & \\
\hline \multirow{5}{*}{ 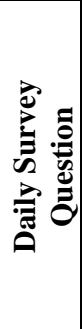 } & $\begin{array}{l}\text { Relationship to } \\
\text { feelings at the time }\end{array}$ & 2.34 & 2.74 & \multirow{5}{*}{ 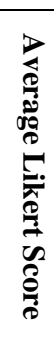 } \\
\hline & $\begin{array}{l}\text { Stress Reduction } \\
\text { (SM) }\end{array}$ & 1.92 & 2.81 & \\
\hline & $\begin{array}{l}\text { Stress Reduction } \\
\text { (browsing SM) }\end{array}$ & 2.64 & 3.21 & \\
\hline & $\begin{array}{l}\text { Stress Reduction } \\
\text { (active SM) }\end{array}$ & 5.54 & 3.08 & \\
\hline & SM Stress Increase & 1.13 & 1.67 & \\
\hline
\end{tabular}

Table 4. Participants indicating High SM Reduction on High Stress Days

\begin{tabular}{|c|l|l|}
\hline Participant & $\begin{array}{c}\text { SM Behavior } \\
\text { (HS) }\end{array}$ & $\begin{array}{c}\text { Role of SM } \\
\text { (Stress Reduction) }\end{array}$ \\
\hline 7 & Browse, Engage & Distraction \\
\hline 10 & Browse & Distraction \\
\hline 11 & Neither & Distraction \\
\hline 13 & Browse & Calming/Release \\
\hline 19 & Browse & Relaxing \\
\hline 21 & Browse & Distraction \\
\hline 25 & Browse, Engage & Distraction \\
\hline 31 & Browse & Escape \\
\hline 32 & Browse, Engage & Distraction \\
\hline 36 & Browse & Distraction \\
\hline
\end{tabular}


Table 5. Textual Extracts

\begin{tabular}{|l|l|}
\hline \multicolumn{1}{|c|}{ Extract } & \multicolumn{1}{|c|}{ Demographics } \\
\hline $\begin{array}{l}\text { (a) I was quite busy at the office } \\
\text { today throughout and didn't get } \\
\text { much time to spend online and } \\
\text { even after work because I went } \\
\text { to the gym }\end{array}$ & $\begin{array}{l}\text { Participant 23 } \\
\text { Male } \\
\text { Day 10 Survey }\end{array}$ \\
\hline $\begin{array}{l}\text { (b) I had a very long stressful } \\
\text { day at work, and I only got a bit } \\
\text { time to browse my Instagram } \\
\text { and Facebook at night, I would } \\
\text { not say it was very de-stressing, } \\
\text { but it did help me to take work } \\
\text { off my mind for a bit }\end{array}$ & $\begin{array}{l}\text { Participant } 11 \\
\text { Day 7 Survey }\end{array}$ \\
\hline $\begin{array}{l}\text { (c) Trying to organize a } \\
\text { university climbing trip over } \\
\text { social media is incredibly } \\
\text { frustrating! }\end{array}$ & $\begin{array}{l}\text { Participant 1 } \\
\text { Female }\end{array}$ \\
\hline $\begin{array}{l}\text { (d) My boyfriend broke up with } \\
\text { me and had changed his profile } \\
\text { to single within the half an hour } \\
\text { that I checked }\end{array}$ & Participant 2 \\
\hline $\begin{array}{l}\text { (e) I felt really sad one day, so } \\
\text { I stopped following thirty } \\
\text { models, I just follow beaches } \\
\text { and South America and Bali, } \\
\text { Australia }\end{array}$ & Day 4 Survey \\
\hline
\end{tabular}

\subsection{WAYS Scoring (High Stress)}

This section of analysis aims to approach the second aim which sought to discover patterns of SM use based on coping style (WAYS). The focus of this section will be on those with high SM stress reduction scores (indicated by a participant selecting either number $6 / 7$ on the Likert scale on the daily survey). This is focused on the qualitative dataset and the coding framework proposed by Skinner [36] (adapted Gaspar, [13]).

Table 6 displays the calculated coping strategies for each of the 38 participants who partook in the study. It shows, 10 out of the 38 participants use 2 or more strategies to reduce their stress. In light of this, it is highly possible that SM could play multiple roles in the reduction of stress.

Interestingly, on the days SM activity was higher, recorded SM data was lower despite it being reported as more useful for stress reduction. Qualitative followup interviews and daily comments provide a greater insight into the results as they suggest that this discrepancy could be due to browsing SM sites as a means of stress reduction. The dataset tells us that looking at images and funny GIFS are a form of escapism, however there is also evidence that using Twitter to vent is utilized as a coping mechanism.

Participants who indicated high stress reduction, as a result of SM on HS days (6/7 on the Likert scale), had the following strategy outcomes when raw scores were calculating from the WAYS: Self Controlling, Escape Avoidant, Positive Reappraisal and Positive Reappraisal/Planful Problem Solving. It is interesting to note that 'Social Support', as a coping strategy, did not appear within the dataset for those with an average HS score. This finding is intriguing as it could suggest that SM cannot compensate as a coping strategy for participants who rely on social support to reduce their stress.

These findings are a good basis for follow-up interventions which can identify SM themes associated with each question on the WAYS scale. Moreover, this could aid evaluation of relevant questions which could lead to the creation of a specific SM Coping Scale - an intervention that [23] identifies the need for.

Table 6. WAYS Scoring

\begin{tabular}{|l|c|}
\hline \multicolumn{1}{|c|}{ Coping Strategy } & Frequency \\
\hline Confrontive Coping & 1 \\
\hline Confrontive Coping/Positive Reappraisal & 2 \\
\hline Escape-avoidant & 16 \\
\hline Planful Problem Solving & 1 \\
\hline Planful Problem Solving/Self-Controlling & 1 \\
\hline Positive Reappraisal & 2 \\
\hline Positive Reappraisal/Escape Avoidant & 1 \\
\hline $\begin{array}{l}\text { Positive Reappraisal/Planful Problem } \\
\text { Solving }\end{array}$ & 2 \\
\hline Seeking Social Support & 2 \\
\hline $\begin{array}{l}\text { Seeking Social Support/Self } \\
\text { Controlling/Positive Reappraisal }\end{array}$ & 1 \\
\hline Seeking Social Support/Self Controlling & 1 \\
\hline Self-Controlling & 6 \\
\hline Self-Controlling/Planful Problem Solving & 2 \\
\hline
\end{tabular}




\section{Discussion}

This research indicates that SM reduces stress with higher average SM stress reduction scores on HS days (2.81 compared to 1.92 on LS days). Further to this, participants reported browsing as a means of distraction from the stressor (both in the moment and to relax after a stressful day).

In light of these findings, Instagram as a tool for stress relief - as a form of escape, could be explored but further research would be required to understand why this platform is related more to stress relief than others, and why browsing is effective and when isn't it effective? We hypothesize, in light of our findings, that there may be a link between stress reduction and mindlessness (i.e. cognitive escape). However, alongside this we must also account for the negative impacts of SM, i.e. participants may initially use this as an escape (a coping mechanism), however this may turn into a negative experience (and increase stress) if their current emotional health is poor. In response to this, observing and producing a framework for the decisions/response of participants to SM platforms could help to produce specific management strategies.

Follow-up interviews provide evidence to suggest that SM can help the loneliness that comes from being in a new environment (which can cause stress), supporting [2,30,35]. This was through connecting virtually with members of their geographically based communities (online communities) to exchange information (and cope with their loss).

There is evidence to support research by [15], that social networking sites are particularly useful for reducing stress in women $[4,16]$. Our research, shown in extracts (c) (d) and (e) within the findings, also supports the findings of Pew $[15,16]$ who found that females were more likely to be stressed by SM. These seemingly contradictory statements could suggest that females are good at finding a way to control the stress caused by SM (seen in extract (e)) in order for it to remain a positive coping mechanism.

According to Naaman et al. [29], individuals use SM platform to post updates on their everyday activities, social lives, feelings, thoughts, and emotions. One could argue that in light of these findings, this as an understanding of SM usage is quite limited for coping with stress as it doesn't comprehend the underlying behaviors (such as browsing). A more suitable approach is to put this into context within the lives of individuals, understanding them as a person (carried out through traditional measures - WAYS).

As noted in the findings, 'Social Support' as a coping strategy did not identify with participants who selected HS reduction (as a result of SM) (5-7 on the Likert scale), on HS days (indicated by selecting 6/7).
This is despite appearing for three others in the dataset. This could suggest that SM cannot be used as a coping strategy for participants who rely on social support to reduce their stress. This therefore provides some suggestion that WAYS can help distinguish between people whom may be stressed (and display it on SM), versus those who do not. This finding is certainly one worth exploring further.

This type of finding provides a greater insight into the role of SM and how it can aid users given their current usage strategies. A multitude of papers have been written about real-life coping, however no theories re-evaluate coping models which incorporate the rise in digital usage and SM by young people, despite its popularity $[23,29]$. We argue that it should not be claimed that SM only causes stress given these results, but further work is required to determine the intricacies that surround SM usage and wellness for self-empowerment.

\section{Conclusion}

Research methods are shifting away from traditional approaches in measuring stress (primarily through personal contact with a health care professional), to live SM data collection which offers real-time information as explored in the theoretical background. Through a rigorous mixed-methods design, this research investigates the influence that SM has in the field of stress reduction for a preliminary understanding of the role of SM in wellness. The aim has been to offer some further insight for the SM debate in relation to mental wellness and an understanding of the positives in response to the negatives that are highlighted in recent research. This has discovered that browsing SM can be a coping tool for stress reduction amongst placement students who have moved locality, and that SM stress reduction is higher when stress is increased.

These are examples of the positive realities that SM can have on stress, moving research forward to a position that provides a foundation for the further investigation of stress reduction on SM and the incorporation of coping mechanisms, utilizing a welldeveloped coping survey (WAYS). Previous research has begun to explore the use of online facilities for coping which has provided helpful insight for us to build our analysis [38], however this research is based purely on survey data and relies on human memory, whereas our study uses live data in the form of daily surveys, SM data and immediate post-study interviews.

Regarding application, we foresee that this and our proceeding research could aid health interventions. As 
discussed, observing behaviors and producing a framework for the decisions/response of participants to SM platforms, could help to produce specific management strategies for educating e-consumers as to the ways SM behavior impacts their health. We are not suggesting in this paper that traditional approaches, such as mindfulness, be replaced by SM (as evidence shows these strategies work successfully). Instead we intend to investigate the ways in which SM (as an innate lifestyle for many) can be utilized beneficially and explore the ways in which SM can be used for coping, something that Van Ingen and Wright enforce in their paper [38].

The results suggest that there is certainly a relationship between self-reported $\mathrm{HS}$ and selfreported SM stress reduction thus provides a justification for the further investigation of SM for stress reduction and potential developments for selfmanagement in wellness. Preliminary qualitative analysis demonstrates that participants recognize the use of browsing for distraction/relaxation and their reported scores indicate that this relates to how they feel at the time.

\section{Limitations and Future Research}

There are a number of limitations to the study. The sample size is relatively small and thus means that the results cannot be readily generalized to a wider population and limits validity for some statistical tests. Moreover, the results presented in this paper are of a preliminary nature and we anticipate further papers with discussions that are focused further on the qualitative SM dataset and coding framework [36], adapted by Gaspar [13]. Future research involves the development and testing of a coping framework that is specifically built for SM (and accounts for each variety of media) - an important development in the digital age. It is important to acknowledge that selfreported scores and comments cannot replace actual measurements. They can however provide important indications as to the wellness of participants and anticipate behaviors on SM.

\section{References}

[1] C. M. Aldwin, Stress, Coping, and Development: An Integrative Perspective. Guilford Press, 2007

[2] S. Bauman and I. Rivers, "Mental Health Treatment”, Mental Health in the Digital Age, Springer, London, 2015, pp. 26-50

[3] BBC, "Instagram 'worst for young mental health' BBC News”, 19-May-2017, available: https://www.bbc.co.uk/news/health-39955295, accessed: 21-Sept-18

[4] L. Beaton, Predicting stress: an investigation into the affects of personality, emotional intelligence, coping and subjective wellness, 2009, available:

https://www.era.lib.ed.ac.uk/handle/1842/3594?show=full

[5] M. D. Bennett and D.B. Miller, “An Exploratory Study of the Urban Hassles Index: A Contextually Relevant Measure of Chronic Multidimensional Urban Stressors" Research on Social Work Practice, 16(3), May 2006, pp. 305-314

[6] S. Cohen, T. Kamarck, and R. Mermelstein, "A global measure of perceived stress", Journal of Health and Social Behavior, 24(4), Dec. 1983, pp. 385-96

[7] S. Cohen et al., "Strategies for measuring stress in studies of psychiatric and physical disorders." Measuring stress: A guide for health and social scientists, 1995, pp. 326

[8] A. S. Daar et al., "Grand challenges in chronic noncommunicable diseases” Nature, 450(7169), Nov. 2007, pp. 494-496

[9] M. De Choudhury et al., "Predicting Depression via Social Media”, ICWSM, 13, 2013, pp. 1-10

[10] S. Folkman and R. S. Lazarus, "Manual for the ways of coping questionnaire”, Consulting Psychologists Press, 1988

[11] S. Folkman and R. S. Lazarus, "Ways of Coping Questionnaire Instrument and Scoring Guide”, 2016, available: https://www.mindgarden.com/158-ways-ofcoping-questionnaire

[12] S. Folkman and J. T. Moskowitz, "Coping: Pitfalls and Promise,” Annual Review Psychology, 55(1), Feb. 2004, pp. 745-774

[13] R. Gaspar et al., "Tweeting during food crises: A psychosocial analysis of threat coping expressions in Spain, during the 2011 European EHEC outbreak”, International Journal of Human Computer Studies, 72(2), Feb. 2014, pp. 239-254

[14] J. Golbeck, “Detecting Coping Style from Twitter”, International Conference on Social Informatics, Springer, Cham, 2016, pp. 454-467

[15] K. Hampton et al., "Psychological Stress and Social Media Use”, Pew Research Center, 2015, available: http://www.pewinternet.org/2015/01/15/psychologicalstress-and-social-media-use-2/, accessed: 07-June-2018

[16] K. Hampton et al., “Social Media and Stress”, Pew Research Center, 2015, available: 
http://www.pewinternet.org/2015/01/15/social-media-andstress/, accessed: 7-June-18

[17] J. M. Koolhaas et al., "Stress revisited: A critical evaluation of the stress concept", Neuroscience and Biobehavioral Reviews, 35(5), pp. 1291-1301

[18] M. Kranzberg, “Science? Technology? Society: It’s as simple as XYZ!” Theory into Practice, 30(4), Sept. 1991, pp. 234-241

[19] E. Krupat, "People in Cities - The Urban Environment and its Effects”, Cambridge University Press, 1985

[20] R. S. Lazarus and J. B. Cohen, "Environmental Stress”, Human Behavior and Environment, Springer, Boston, 1977, pp. 89-127

[21] R.S. Lazarus and S. Folkman, Stress, Appraisal and Coping, Springer, New York, 1984

[22] F. Lederbogen et al., "City living and urban upbringing affect neural social stress processing in humans”, Nature, 474(7352), 23 June 2011, pp. 498-501

[23] M. Leiner et al., "Is there a need to modify existing coping scales to include using electronic media for coping in young people?” Frontiers in Pediatrics, 2-Jan-2014, p. 127

[24] S. Liu et al., "Using Real-Time Social Media Technologies to Monitor Levels of Perceived Stress and Emotional State in College Students: A Web-Based Questionnaire Study”, JMIR Mental Health, 4(1), 2017, available: http://doi.org/10.2196/mental.5626

[25] W. B. Lober and J. L. Flowers, "Consumer Empowerment in Health Care Amid the Internet and Social Media”, Seminars in Oncology Nursing, 27(3), Aug. 2011, pp. 169-182

[26] C. A. Mckim, "The Value of Mixed Methods Research: A Mixed Methods Study”, Journal of Mixed Methods Research, 11(2), 2017, pp. 202-222

[27] S. M. Monroe, "Modern approaches to conceptualizing and measuring human life stress”, Annual Review Clinical Psych., 4, 2008, pp. 33-52

[28] R. H. Moos, Human adaptation: coping with life crises. Health, 1976

[29] M. Naaman, J. Boase and L. Chih-Hui, "Is it Really About Me? Message Content in Social Awareness Streams," 2010, available: http://www.scribd.com/doc/20397644/Twitter-Study, accessed: 7-June-18

[30] C. H. Procopio and S. T. Procopio, "Do You Know What It Means to Miss New Orleans? Internet Communication, Geographic Community, and Social
Capital in Crisis”, Journal Applied Comm. Research, 35(1), Feb. 2007, pp. 67-87

[31] A. Raviv et al., "Moving as a stressful life event for adolescents", Journal of Community Psychology, 18(2), 1990, pp. 130-140

[32] S. Regel and S. Joseph, Post-traumatic stress, Oxford University Press, 2017

[33] RSPH and Young Health Movement. "RSPH Instagram ranked worst for young people's mental health”, available: https://www.rsph.org.uk/about-

us/news/instagram-ranked-worst-for-young-people-smental-health.html), accessed 22-Sept-18

[34] H. Selye, “The Stress Concept” Canadian Medical Association Journal, 115(8), 1976, p.718

[35] I. Shklovski et al., "Technology Adoption and Use in the Aftermath of Hurricane Katrina in New Orleans", American Beh. Scientist, 53(8), Feb. 2010, pp. 1228-1246

[36] E. A. Skinner. et al., "Searching for the structure of coping: A review and critique of category systems for classifying ways of coping,” Psychological Bulletin, 129(2), 2013, pp. 216-269

[37] M. D. Sykora et al., "Emotive Ontology: Extracting Fine-Grained Emotions from Terse, Informal Messages”, 2013

[38] E. Van Ingen and K. B. Wright, "Predictors of mobilizing online coping versus offline coping resources after negative life events,” Computer Human Behavior, 59, June 2016, pp. 431-439

[39] D. Watson, L. A. Clark, and A. Tellegen, "Development and validation of brief measures of positive and negative affect: The PANAS scales", Journal of Personality and Social Psych., 54(6), 1988, pp. 1063-1070

[40] A. Wildavsky, and D. Hammer, "The open-ended, semi structured interview: An (almost) operational guide”, Craftways, Routledge, 2018, pp. 57-101

[41] World Health Organization., "Depression and Other Common Mental Disorders, Global Health Estimates”, 2017, available:

http://apps.who.int/iris/bitstream/handle/10665/254610/WH O-MSD-MER-2017.2-eng.pdf?sequence $=12017$, accessed: 21-Sept-18

[42] K. B. Wright et al., "Health-related Support Groups on the Internet: Linking Empirical Findings to Social Support and Computer-mediated Communication Theory”, Journal of Health Psychology, 8(1), Jan. 2003, pp. 39-54 